\title{
The effect of rotational speed on quality of sound vertical centrifugal castings tin
}

\author{
Mahantesh S. Tattimani ${ }^{1, *}$, Maheswar C.Y. ${ }^{1}$, Babu Reddy $^{2}$, Shrikant Badi $^{1}$, Ambadas $^{2}$, \\ and Anandkumar S. Malipatil ${ }^{2}$ \\ ${ }^{1}$ Department of Mechanical Engineering, SKSVM Agadi College of Engineering \& Technology, Lakshmeshwar, India \\ ${ }^{2}$ Department of Mechanical Engineering, VTU's Centre for Postgraduate Studies, Kalaburagi, India
}

Received: 3 April 2021 / Accepted: 27 June 2021

\begin{abstract}
Centrifugal casting plays a key role in manufacturing processes. In this process, the flow of the molten metal in particular, plays a significant role in defining the quality of final cast tube. The current study is an experimental work that focuses on the effect of fluid flow speeds on the quality of final cast product. The study was conducted using the vertical centrifugal casting with tin as the primary raw material. It is observed from the study that for the given manufacturing conditions, a speed $1050 \mathrm{rpm}$ produced the sound castings. The micrographic studies of these cast products revealed an excellent grain structures. The improvement in the material hardness was also observed.
\end{abstract}

Keywords: Vertical centrifugal casting / optimum speed / tin / hardness / grain structure

\section{Introduction}

Centrifugal casting is an important manufacturing process. It uses the centrifugal force to fill the molten metal into the mold cavity. There are two major types of commonly used centrifugal casting methods; they are horizontal centrifugal casting and vertical centrifugal casting. Of these, the vertical centrifugal casting in particular is employed to generate cylindrical and hollow tubes where diameter is more than the length. In this process a molten metal is poured into the rotating mold cavity and due to the centrifugal force, molten metal moves to the inner surface of the rotating mold and solidifies slowly. The flow of the molten metal in casting plays a significant part in determining the quality of the final castings. The behavior of the fluid flow in turn depends on several parameters, namely, rate of fabrication, process instability, and speed.

The centrifugal force in the vertical centrifugal process assists in the refinement of the metal by separating the low weight non- metallic towards the axis of the mould. The major benefit is the rapid directional solidification from outer surface to inner surface, leading to a modification in grain structure, which results in better strength and other mechanical properties. Grain modification in particular is considered to be a valuable means to promote the material properties [1-3] as it improves fatigue strength, ductility, and stress corrosion resistance.

\footnotetext{
* e-mail: mahantesh.s.t@gmail.com
}

One of the major factors that determine the quality of cast in the vertical centrifugal casting is the speed of the rotating mould. In particular we were interested in the effect of rotational speed on hardness, microstructure and appearance of the castings.

Roy et al. [4] discussed the effect of mould rotational speed on parameters namely hardness, grain structure and impact. Here, Al-13Si alloy cast tubes were fabricated from metallic spilt mould at several mould speeds, namely 0 to 120 in the steps of 30 . They inferred that rotational speed bore a direct impact on the smoothening of the grain structure and allocation of essential phases within it. The study showed that good grain structure was found at an optimal rotational speed of $60 \mathrm{rpm}$. Singh and Ojha [5] manufactured the cast tubes made of leaded hypoeutectic Al-Si alloy, by vertical centrifugal casting apparatus paired by means of impeller mixing bottom discharge method. The experiments were carried out at a rotational speed of 1200 to $1700 \mathrm{rpm}$ with an interval of $100 \mathrm{rpm}$ and they observed that the optimal speed was found to be $1600 \mathrm{rpm}$ with their experimental conditions.

There also have been numerical studies to simulate the molten metal filling process in the micro-scale during the centrifugal casting [6]. The authors derived the similarity criterion and equations for metal flows in micro-scale space. They simulated the flow process to visualize and to assess the flow process qualitatively. Qudong et al. [7], among other things, evaluated the influence of mould rotational 
speed on the grain-structure of a $\mathrm{Zn}-27 \mathrm{Al}-x \mathrm{Mg}-y \mathrm{Si}$ alloy and their composites, and found that when the mould rotational speed increased, thickness of inside layer also increased whereas outer layer thickness decreased. The grain dimensions of the particles were found to decrease in outer as well as inner layers of cast tube. Rao et al. $[8,9]$ in their study on the effect of mould speed found casting to develop defects both at high and low speeds. They found that defects are minimal at a particular optimum speed. They attributed this to the behavior of molten metal during the processes of teeming and solidification. It was further examined that at a lower speed, the Taylor flow, Couette flow and Ekmann flow were predominant and produced casts with uneven interior surface.

Prasad et al. [10] examined the influence of the rotational speed in the formation of grain composition of the cast tube. The variation in grain size was found to be more at lower rotational speeds than at higher rotational speeds. Ping [11] produced a multi scale model in order to simulate the grain structure development in the process of the solidification of Tin alloys using vertical centrifugal casting method. The cast tubes studied indicated the appearance of the fine grain structure to the coarse grain structure from the interior surface to exterior mould surface. Also, the area of equiaxed section was found to increase along with rotational speed. Kim et al. [12] fabricated cast tubes of various diameters by centrifugal casting technique. After examination, it was found that the grain structure of the cast tube was uneven and porosity gradient was present alongside the thickness of the specimen. Madhusudhan et al. [13] performed the experimental studies on the solidification rate of centrifugal casting. The mould rotational speed again was found to have a vital role in the cooling rate of the casting. Chirita et al. [14] discussed the advantages of the parts fabricated by vertical centrifugal casting and conventional gravity casting, taking into consideration, the mechanical properties of the castings. The study indicated the centrifugal force in the centrifugal casting increased the fracture strain by $160 \%$ and fracture strength by $35 \%$ over the gravity casting method. In addition, the Young's modulus too increased by $18 \%$ while the increase in fatigue length was about $1.5 \%$

An optimization study is used to find the best set of parameters that will produce the optimal output. Optimization techniques are commonly used in manufacturing processes. A typical manufacturing process involves multiple parameters and hence a comprehensive study would involve varying all the parameters according to an established optimization technique. For example, Fatih Erdemir [15] extensively studied the effect of milling parameters such as milling time, milling speed, and ball to powder ratio using various methods. Thus, an ideal optimization study should be done considering all these parameters. However, the focus of present study is to just study the single parameter of speed of mould rotation on the quality of cast tubes as the authors believe speed can be an important parameter and that it will help in optimizing the cost of production using vertical centrifugal casting. Besides, the studies involving the cast products made of Tin are very few and the authors hope add another

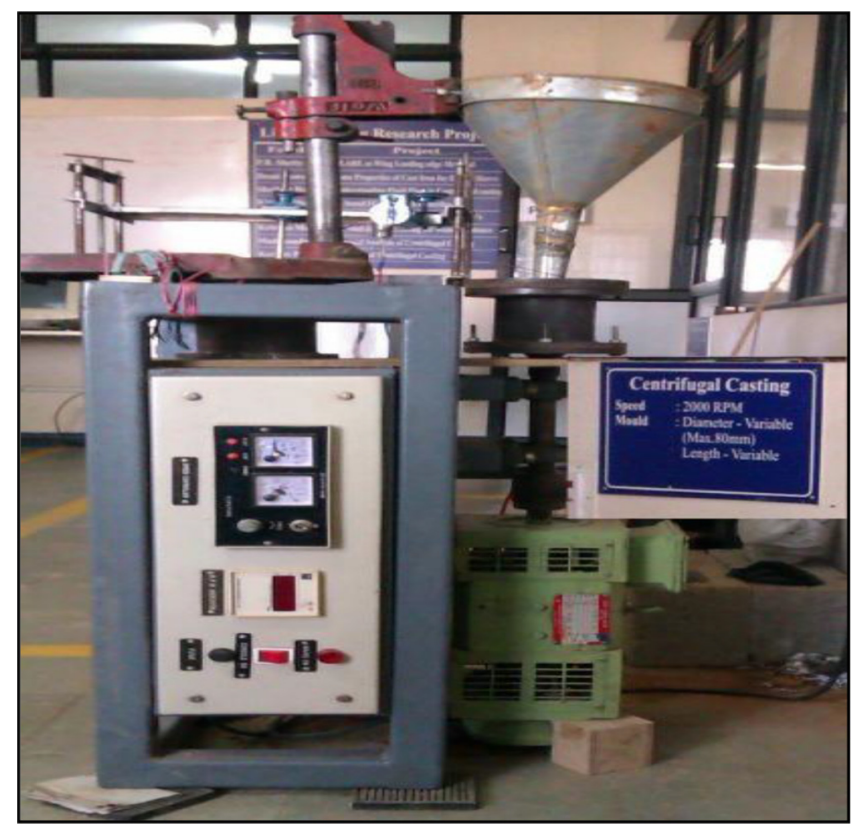

Fig. 1. Vertical centrifugal casting machine.

experimental work into the body of knowledge with respect to the centrifugal casting especially the one using Tin as the molten material.

\section{Experimental procedure}

The experimental set up consists of vertical centrifugal casting apparatus as indicated in Figure 1. The shaft of the 2HP DC motor drives the machine and can produce differing mould rotational speeds ranging from 30 to $3000 \mathrm{rpm}$. The device is equipped with an accurate speed controller. The electric resistance furnace was employed for melting the metals at $450^{\circ} \mathrm{C}$. The dimension of true cylinder is $\phi 82 \times 80 \mathrm{~mm}$ and produces castings of $8 \mathrm{~mm}$ thick. The actual dimension of specimen produced is $80 \times 10 \mathrm{~mm}$

As noted earlier, Tin is employed as the molten material for experimentation owing to its lower melting point. Tin has a melting point of $231.9^{\circ} \mathrm{C}$ and the entire metal casting process is carried out at a temperature of about $450^{\circ} \mathrm{C}$. The mould rotational speeds used are $650 \mathrm{rpm}, 850 \mathrm{rpm}$, $1050 \mathrm{rpm}$, and $1250 \mathrm{rpm}$. During the experimentation, mould rotational speed is set to the values mentioned above and then melt is transferred to the die. It is then allowed to rotate for some time to guarantee the adequate solidification. Cast products were collected at the end of each process. During optimum rotational speed, it was observed that the molten metal moved up and held firmly to the rotating mould wall without skidding.

The hardness of cast product, in this case, tubes, is ascertained by Rockwell hardness ( $\mathrm{RH})$ apparatus. The hardness values for both internal layers and external layers of the specimen are measured. 


\subsection{Appearance of the castings}

As is well known, in centrifugal casting, due to the centrifugal force, the molten metal is thrown towards the die away from the central axis of the mould. The metals then impinge against mould and try to ascend upwards. At the low speed of $650 \mathrm{rpm}$, the gravitational downward pull force dominates over the centrifugal force, and hence due to this imbalance of forces, uneven shaped cast tubes were produced. A sample cast product is indicated in Figure 2a. As the mould rotational speed is enhanced from 650 to $850 \mathrm{rpm}$, the centrifugal force is insufficient to produce the complete cylinder as indicated in Figure 2b. The correct balancing of both the centrifugal force and gravitational force occurs at $1050 \mathrm{rpm}$ speed, when the molten metal rises

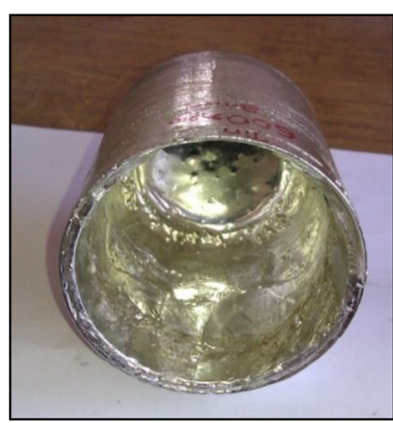

(a)

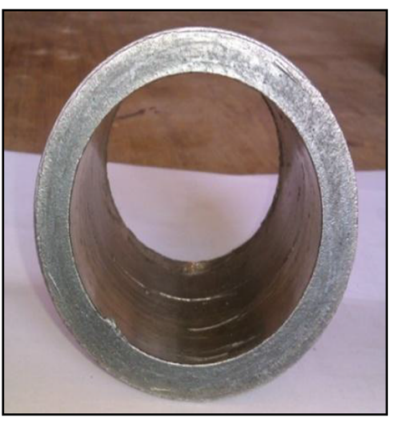

(c)

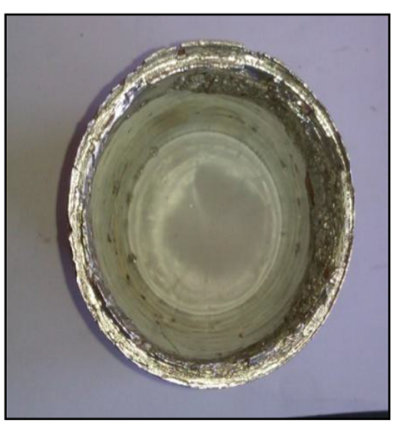

(b)

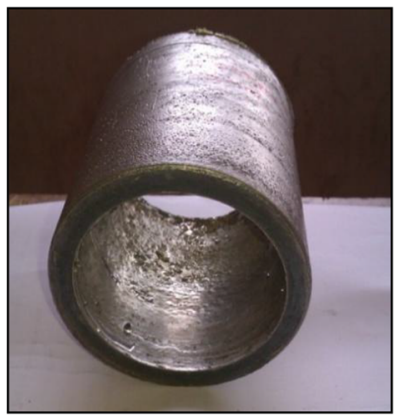

(d)
Fig. 2. Casting of $8 \mathrm{~mm}$ thick Tin rotated at a speeds of (a) $650 \mathrm{rpm} \mathrm{(b)} 850 \mathrm{rpm} \mathrm{(c)} 1050 \mathrm{rpm}$ (d) $1250 \mathrm{rpm}$. the mould length without any slippery, producing even cast tubes. A sample cast product at this speed is shown in Figure 2c. As the speed is increased to $1250 \mathrm{rpm}$, owing to larger forces, the molten metal strikes mould's the upper flange with high acceleration and subsequently slips in downward direction, producing uneven shaped cast tubes as indicated in Figure 2d.

\section{Results and discussion}

\subsection{Microstructure details}

The flow of the molten metal affects the grain structure of castings. It hinders the development of dendritic configurations in radial direction. The grains were organized unevenly and inappropriately for mould speeds of $650 \mathrm{rpm}$ and $850 \mathrm{rpm}$ and the grain structures are indicated in Figures 3 and 4 .

The rise in the mould rotational speed to $1050 \mathrm{rpm}$ facilitates the molten metal to remain in a stagnant condition wherein it produces an even cast tubes. The fine structures are observed across the thickness and relevant grain structure of the cast tubes are as indicated in Figure 5 .

When the speed was increased to $1250 \mathrm{rpm}$, the resulting castings were again found to be un-even. This was due to relatively large centrifugal force at this high speed. The resulting coarse grain structures along the thickness are shown in Figure 6. At this speed, the slip exerted through the melt hinders the solidification rate and the coarse grains are produced at the interior surface of cast tube.

\subsection{Intercept length of soft phase}

Figure $7 \mathrm{a}$ indicates the grain sizes of castings at $650 \mathrm{rpm}$. Here fraction of the grains of solid phase, $L \alpha$, in the range of 40 to $50 \mu \mathrm{m}$, is as high as $85 \%$. The microstructure showed a few large primary coarse grains with, intercept length up to $90 \mu \mathrm{m}$. This clearly indicates the uneven flow of melt and decrease in cooling rate.

At $850 \mathrm{rpm}$, Figure 7b, the grain of solid phase $L \alpha$, is as high as $88 \%$ grains in the range of $35-45 \mu \mathrm{m}$. Even though the size of grain is lowered because of further rise in melt,

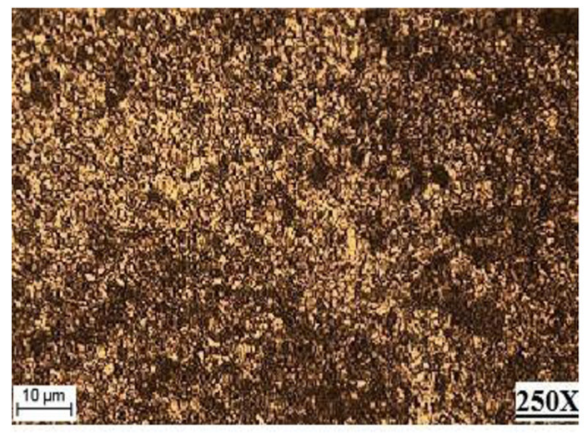

(a)

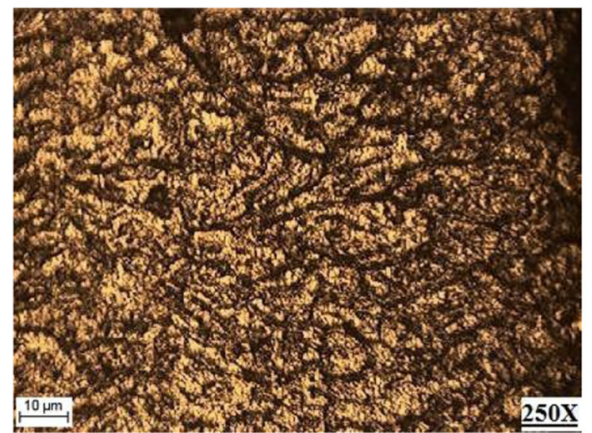

(b)

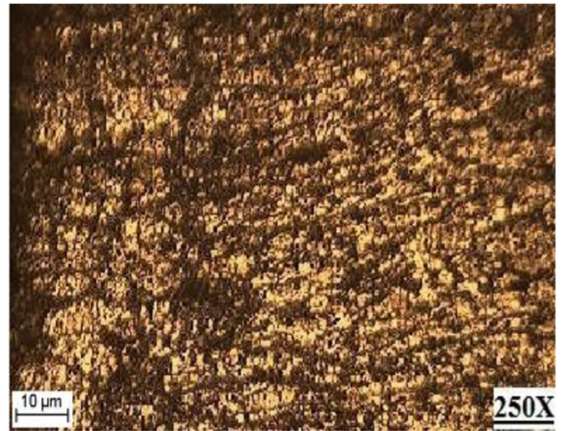

(c)

Fig. 3. Grain structure of $8 \mathrm{~mm}$ Tin castings for interior, middle as well as external surfaces for speeds of $650 \mathrm{rpm}$. (a) $650 \mathrm{rpm}$ interior surface. (b) $650 \mathrm{rpm}$ middle surface. (c) $650 \mathrm{rpm}$ external surface. 


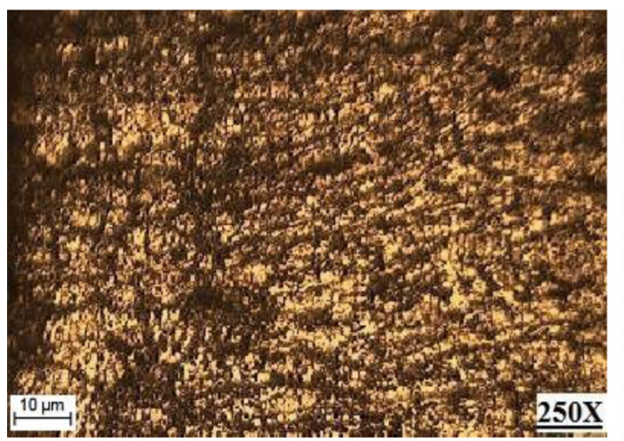

(a)

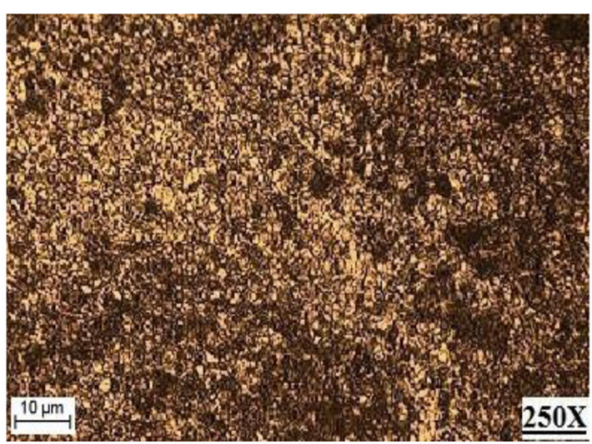

(b)

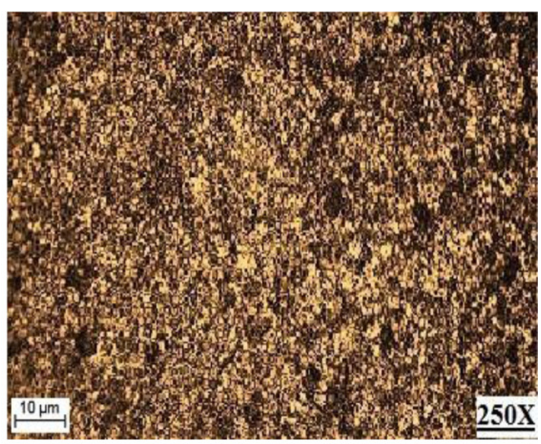

(c)

Fig. 4. Grain structure of $8 \mathrm{~mm}$ Tin castings for interior, middle as well as external surfaces for speeds of $850 \mathrm{rpm}$. (a) $850 \mathrm{rpm}$ interior surface. (b) $850 \mathrm{rpm}$ middle surface. (c) $850 \mathrm{rpm}$ external surface.

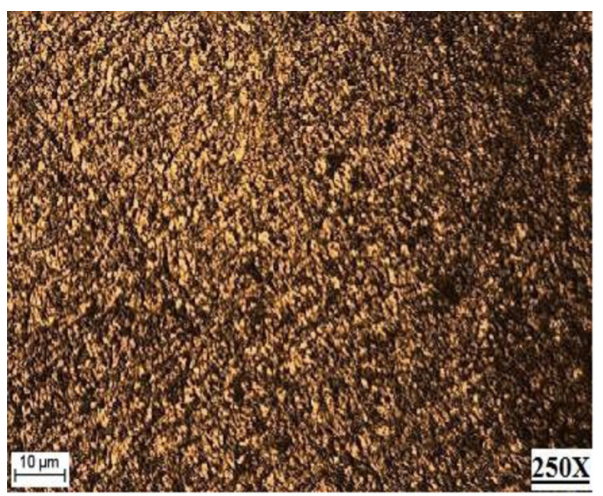

(a)

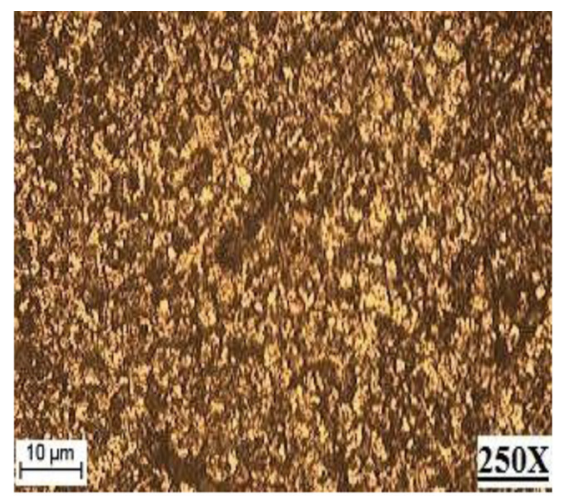

(b)

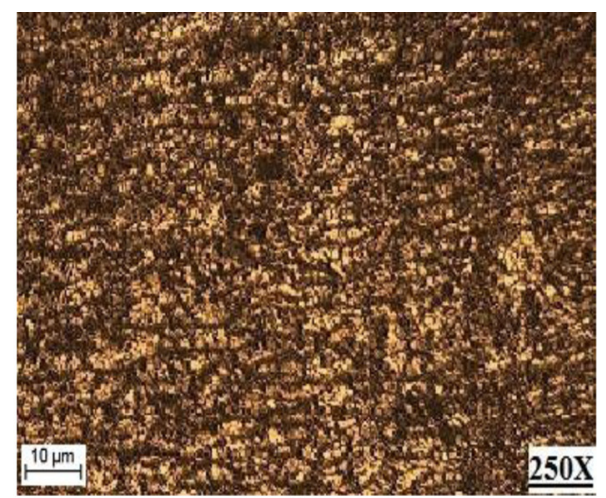

(c)

Fig. 5. Grain structure of $8 \mathrm{~mm}$ Tin castings for interior, middle as well as external surfaces for speeds of $1050 \mathrm{rpm}$. (a) $1050 \mathrm{rpm}$ interior surface. (b) $1050 \mathrm{rpm}$ middle surface. (c) $1050 \mathrm{rpm}$ external surface.

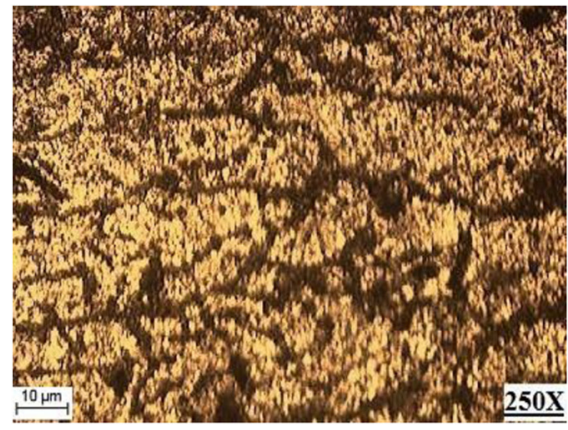

(a)

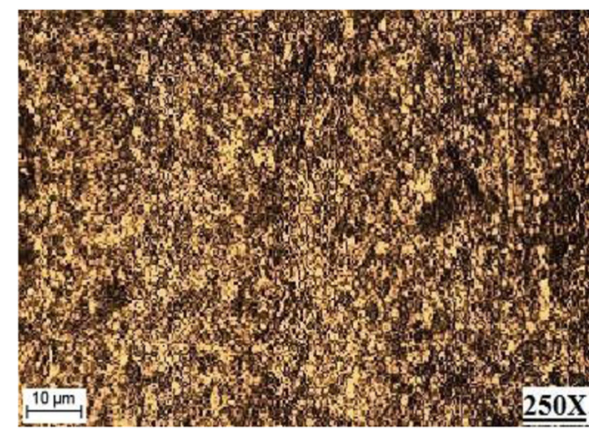

(b)

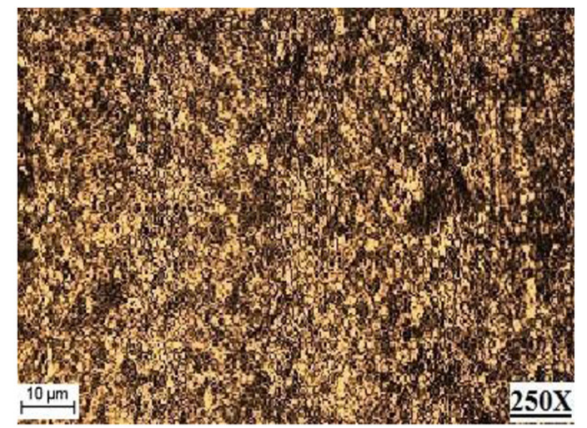

(c)

Fig. 6. Grain structure of $8 \mathrm{~mm}$ Tin castings for interior, middle as well as external surfaces for speeds of $1250 \mathrm{rpm}$. (a) $1250 \mathrm{rpm}$ interior surface. (b) $1250 \mathrm{rpm}$ middle surface. (c) $1250 \mathrm{rpm}$ external surface.

the formation of coarse grains is evident by again having a lower cooling rate of the process. In addition to this, the heat transfer in the mold is poor due to its half way casting during its rotation.

For sound casting to be produced, the molten metal should occupy the entire mold surface and then solidify. To produce this, higher mold speed is required to lift the melt with low viscosity and overcome melt weight. This can be achieved when the mold is rotated at optimum speed of $1050 \mathrm{rpm}$. Here, the cooling rate is comparatively higher as compared to other rotational speeds because of which, fine grains with $15-20 \mu \mathrm{m}$ and as high a fraction as $90 \%$ are observed in the castings as shown in Figure $7 \mathrm{c}$. 


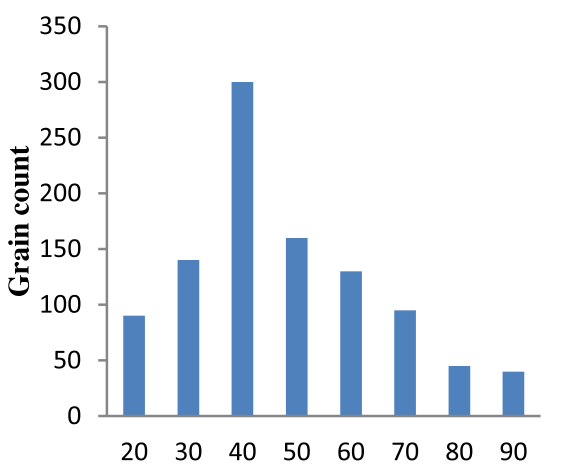

Intercept length of softphase $\operatorname{La}(\mu \mathrm{m})$

(a)

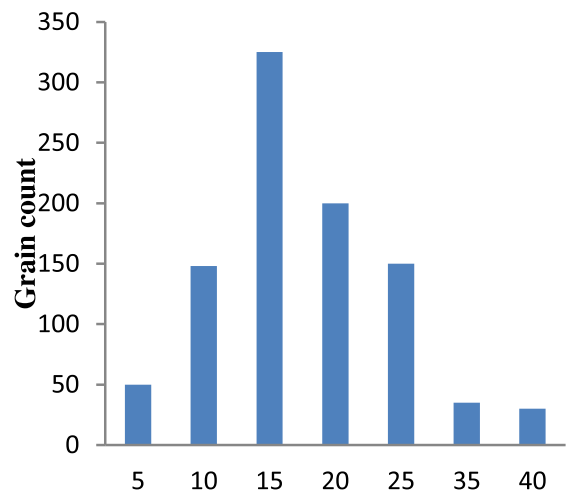

Intercept length of softphase $L \alpha(\mu \mathrm{m})$

(c)

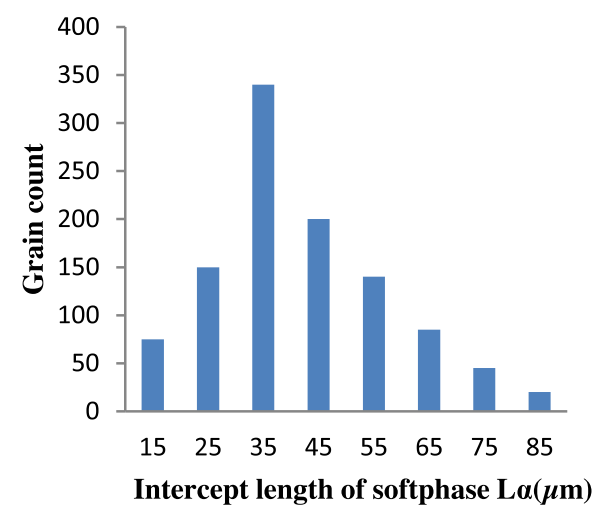

(b)

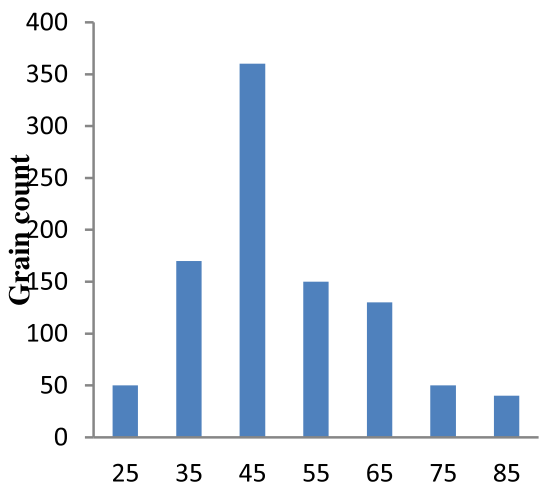

Intercept length of softphase $\operatorname{L} \alpha(\mu \mathrm{m})$

(d)

Fig. 7. Grain count numbers v/s intercepts lengths of soft phase L $\alpha$ (Tin) for (a) $650 \mathrm{rpm}$ (b) $850 \mathrm{rpm}$ (c) $1050 \mathrm{rpm}$ and (d) $1250 \mathrm{rpm}$.

When the speed rose to $1250 \mathrm{rpm}$, the lift becomes too high and it hits the upper flange of the mold and the slippery of the melt occurs, which results in non-uniform castings and large intercept lengths as shown in Figure 7d.

\subsection{Hardness values, tensile and impact strength}

The hardness value depends on the mould rotational speed because this influences the flow ability of a molten metal in the mould. Figure 8 indicates the variation of hardness at different rotational speeds of mould. The hardness of the inner surface is found to be high compared to that of outer surface. At the inner cast tubes, the vortex motion of air takes away major portion of the heat and hence high hardness value is recorded. The uniform and large hardness values were seen at the external, middle and interior sections of castings at optimal mould speed of $1050 \mathrm{rpm}$ due to their fine grain structures. Deviation in the hardness values were detected for the cast tube formed at a speed values lower and higher than $1050 \mathrm{rpm}$ due to the uneven distribution of the melt. The graphs of $\mathrm{RH}$ for different indentation locations at speeds of $650 \mathrm{rpm}, 850 \mathrm{rpm}$, $1050 \mathrm{rpm}$, and $1250 \mathrm{rpm}$ are indicated in Figure 8a-d.

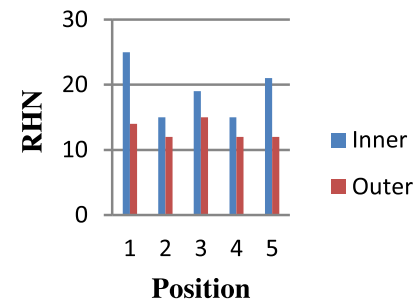

(a)

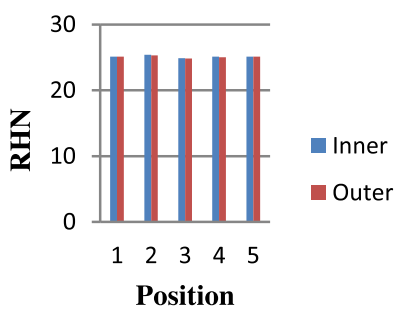

(c)

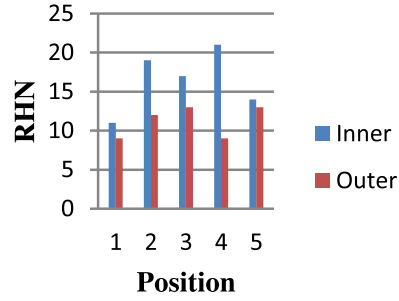

(b)

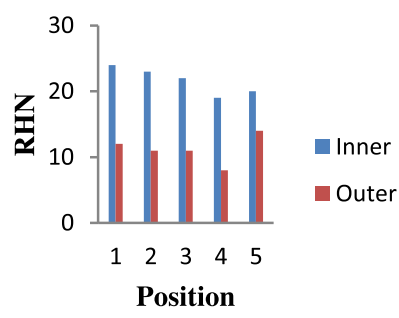

(d)

Fig. 8. Rockwell hardness values vs. indentation point for $8 \mathrm{~mm}$ Tin cast tubes at speeds of (a) $650 \mathrm{rpm}$ (b) $850 \mathrm{rpm}$ (c) $1050 \mathrm{rpm}$ and (d) $1250 \mathrm{rpm}$. 


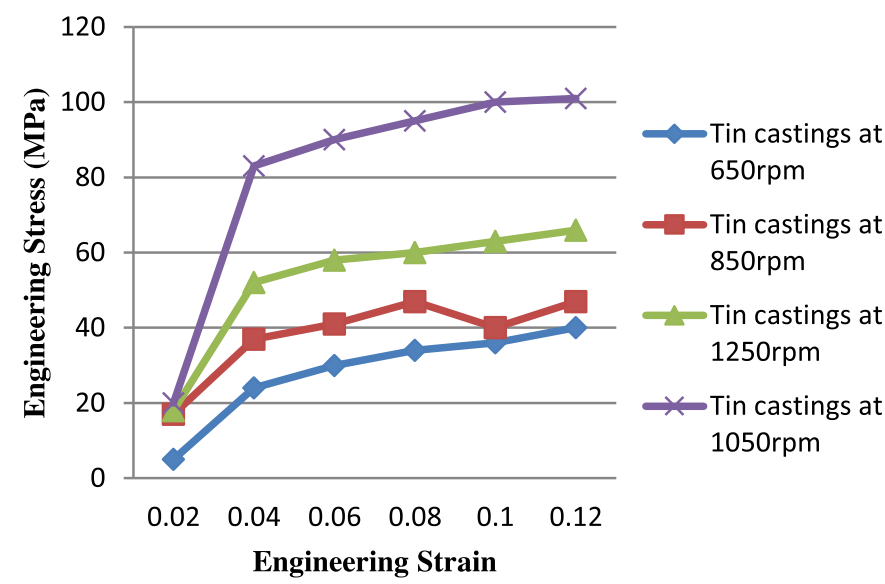

Fig. 9. Engineering stress vs engineering strain for $8 \mathrm{~mm}$ Tin cast tubes at speeds of $650 \mathrm{rpm}, 850 \mathrm{rpm}, 1050 \mathrm{rpm}$ and1250 rpm.

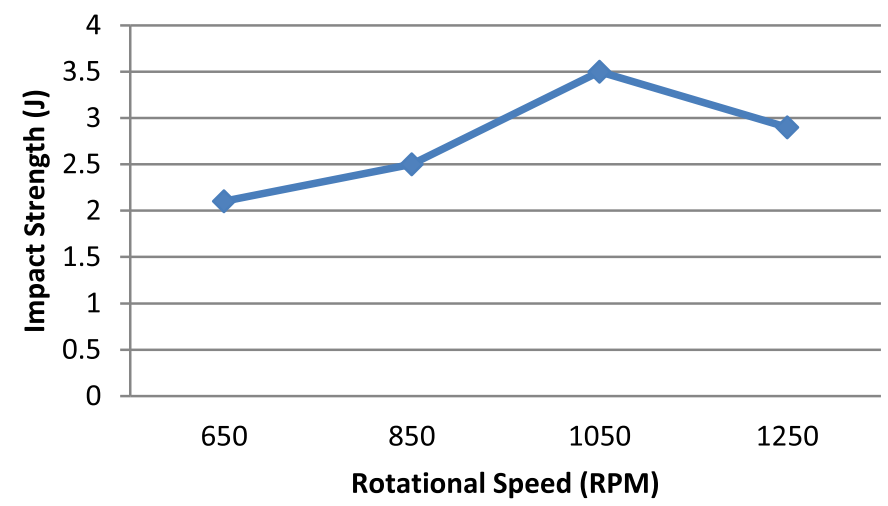

Fig. 10. Impact strength of $8 \mathrm{~mm}$ Tin cast tubes at speeds of $650 \mathrm{rpm}, 850 \mathrm{rpm}, 1050 \mathrm{rpm}$ and $1250 \mathrm{rpm}$.

Figure 9 indicates the tensile strength of $8 \mathrm{~mm}$ cast tubes at different rotational speeds. It is observable from the graph that tensile strength at $1050 \mathrm{rpm}$ is higher compared to tensile strengths at all others speeds. This is due to the formation of uniform cast and fine grains throughout its length. Uniform spreading of the melt and rise in the solidification rate assist in improving the grain structures. This will in turn help to improve the tensile and impact strength of the cast tube (as seen in Figs. 9 and 10). But in case of the speeds above and below the optimum speed of $1050 \mathrm{rpm}$, the coarse grains were observed and uneven formation of castings gave rise to lower tensile and impact strength.

\section{Conclusions}

The whole idea of the present study was to study the effect of rotational speed on the quality of casting. The parameters that were measured are appearance of grain structure, hardness, and impact strength. At lower speeds, the gravitational force dominated while at higher speeds the centrifugal force dominated. Both resulted in the uneven casting. In this work an optimal speed of 1050 was found have a proper balance of gravitational and centrifugal force.

The distribution of grain structure was non-uniform through the thickness of the casting at lower and higher speeds. The optimal speed of $1050 \mathrm{rpm}$ produced uniform through thickness grain structure. The hardness and impact strengths were also affected by the speed of rotation. The hardness and impact strengths obtained were also high at the optimal speed.

\section{References}

1. A. Shailesh Rao, M.S. Tattimani, S.S. Rao, Effect of rotational speeds on the cast tube during vertical centrifugal casting process on appearance, microstructure and hardness behavior for Al-2Si alloy, Metal. Mater. Trans. B 46 (2015) 793-799

2. Y. Jaluria, Fluid flow phenomena in materials processingthe 2000 freeman scholar lecture, J. Fluid. Eng. Trans. ASME 123 (2001) 173-210

3. P.G. Mukunda, A. Shailesh Rao, S.S. Rao, Influence of rotational speed during centrifugal casting on sliding wear behaviour of the Al-2Si alloy, Front. Mater. Sci. China 3 (2009) 339-344

4. B.C. Ray, U.K. Mohanty, B.B. Verma, Influence of crucible rotation speed on hardness, microstructure and impact properties, Trans. Indian Inst. Metals 59 (2006) 57-63

5. J.K. Singh, S.N. Ojha, Preparation of leaded Al-Si alloys by modified vertical centrifugal casting machine, Int. J. Eng. Innov. Technol. 2-9 (2013) 230-234

6. R. Ming-Xing, W. Guo-Tian, L. Bang-Sheng, W. Zhen-Long, F. Heng-Zhi, Flow equation and similarity criterion during centrifugal casting in micro-channel, Trans. Nonferrous Metals Soc. China 24 (2014) 1506-1511

7. W. Qudong, C. Yongjun, C. Wenzhou, W. Yinhong, Centrifugally cast Zn-27Al-xMg-ySialloys and there insitu (Mg2Si+Si)/ZA27 composites, Mater. Sci. Eng. A 394 (2005) 425-434

8. A. Shailesh Rao, P.G. Mukunda, S.S. Rao, Inference of optimal speed for sound centrifugal casting of tin, Can. Metal. Quart. Mater. Sci. 48 (2009) 157-166

9. A. Shailesh Rao, P.G. Mukunda, S.S. Rao, Influence of teeming temperature of molten metal of tin during centrifugal casting, Int. J. Cast Metal Res. 23 (2010) 51-54

10. K.S. Keerthi Prasad, Analysis of fluid flow in centrifugal casting, Front. Mater. Sci. China 4 (2010) 103-110

11. W.S. Ping, L.D. Rong, G.J. Jie, L.C. Yun, Numerical simulation of microstructure evolution of Ti $6 \mathrm{Al}-4 \mathrm{~V}$ alloy invertical centrifugal casting, Mater. Sci. Eng. A 426 (2006) 240-249

12. H.K. Kyhung, J.C. Seong, J.Y. Kyung, Centrifugal casting of alumina for membrane application, J. Membrane Sci. 199 (2002) 69-74

13. Madhusudhan, S. Narendranath, G.C. Mohankumar, P. Mukunda, Experimental study on rate of solidification of centrifugal casting, Int. J. Mech. Mater. Eng. 5 (2010) 101-105 
14. G. Chirita, D. Soares, S. Filipe, Advantages of the centrifugal casting technique for the production of structural components with Al-Si alloys, Mater. Des. 29 (2008) $20-27$
15. F. Erdemir, Study on particle size and X-ray peak area ratios in high energy ball milling and optimization of the milling parameters using response surface method, Measurement 112 (2017) 53-60

Cite this article as: Mahantesh S. Tattimani, Maheswar C.Y., Babu Reddy, Shrikant Badi, Ambadas, Anandkumar S. Malipatil, The effect of rotational speed on quality of sound vertical centrifugal castings tin, Manufacturing Rev. 8, 21 (2021) 